\title{
A Corpus-Based Critical Discourse Analysis of 'Chinese Model' on Africa Mainstream Newspapers
}

\author{
Xin Liu \\ School of Foreign Languages, \\ Dalian University of Technology, Dalian, China \\ Wenyu Liu \\ School of Foreign Languages, \\ Dalian University of Technology, Dalian, China
}

\begin{abstract}
In recent years, China's economy and international influence grows increasingly, "Chinese model", China's successful development experience, has been extensively discussed around the world. As friendship and communications between China and Africa becomes more osculation, Africa's attitudes towards "Chinese model" matters much and cannot be ignored. In order to objectively and systematically examine African cognition and attitudes towards "Chinese model", this research collects most of the news reports on "Chinese model" in African mainstream newspapers from 2000 to 2017. Assisted by corpus software, this paper conducts an analysis on Co-occurrence Network of Words around Chinese model, keywords of the texts, and concordance lines of Chinese model. Furthermore, semantic prosody will be explored in concordances. The findings suggest that: (1) On the discussion of Chinese model, the focus of African media is primarily on their economic development, China's investment, trade and cooperation, and expectation to draw upon Chinese development experience to relieve them from poverty. (2) Most of the reports on Chinese model are strongly associated with economy, and only a few reports involves with politics. (3) On the point of replicating Chinese model in facilitating African development, the majority of Africans are affirmative of this approach. There are only a few reports in which people show their uncertainty and worries about the prospect of applying Chinese model in Africa.
\end{abstract}

Keywords: Chinese model; African media; Critical Discourse Analysis; corpus

\section{INTRODUCTION}

With the rapid development of China's economy and its international influence on the world stage, the rising power has drawn worldwide attention. Even against the backdrop of financial crisis sweeping across the world a few years ago, China stayed prosperous, harmonious and stable, which formed a stark contrast with these affected regions which are based on the old "Washington consensus" model. Therefore, "Chinese Model", "China's Experience", etc., have aroused extensive discussions in political, economic and academic circles round the world. It is generally acknowledged that the discussion on "Chinese model" originates from a research report, entitled "Beijing Consensus" in which Joshua Cooper Ramo carried out a comprehensive and rational analysis of China's great deed in reform and opening-up and described the development model that China has explored in line with its own national conditions as "Beijing model", namely Chinese model. According to Ramo, this series of development thoughts is not only suitable for China, but also for other developing countries who seek for economic growth.

These years, as the economic and trade cooperation, political association and cultural exchange between China and Africa tighten, Sino-Africa has formed a new comprehensive strategic 
cooperative partnership, embracing mutual trust, assistance and benefits. Meanwhile, Africa, as the second largest continents with second largest population, has long been suffering from poverty. Since both China and Africa share common mission of development in peace and stability and China is seen great achievements made over the past few years, African countries start to consider the effective alternative of Chinese model to relieve them from the state of poverty.

Moreover, Sino-Africa friendly cooperation is of utmost importance to both sides, and how Chinese model is constructed on African mainstream newspapers also matters much in that it not only concerns China's diplomatic image, but also its discourse power and international influence. But in spite of a rising discussion or study about "Chinese model" these years, these studies are mainly focuses on the European mainstream newspapers on China's national image and Chinese model, ignoring the cognition of African developing countries on Chinese model. On these basis, African countries' attitudes towards Chinese model is in necessary and urgent need to be examined. So to objectively and systematically examine African cognition and attitudes towards "Chinese model" and to reveal the discursive construction on "Chinese model", this paper tries to conduct a comprehensive and multi-perspective analysis on African mainstream newspapers on "Chinese model", assisted by corpus software.

\section{LITERATURE REVIEW}

Discourse is described as a form of "social practice" by Norman Fairclough and Ruth Wodack (2013), which implies "a dialectical relationship between a particular discursive event and the situation, institution and social structure that frame it: the discursive event is shaped by them, but it also shapes them" (Wodack 1996: 15). Discourse analysis is the study of what and how people narrate and the social consequences of what they narrate. On the basis of discourse analysis, Critical Discourse Analysis(CDA), was put forward and further developed into an important interdisciplinary approach to the study of discourse. It focuses on the "linguistic description of the language text, interpretation of the relationship between the discursive processes and the text, and explanation of the relationship between the discursive processes and the social processes" (Fairclough 1989: 97). This research approach enables people to analyze specific texts and moreover to form an understanding of the relationship between discourse and social or political phenomena.

"Chinese model", "China's Experience”, etc., are all substantially regarded as political discourse, which is a tool for a country to deal with diplomacy and public opinion. The ideology and values embodied in political discourse can, to some extent, reflect and influence citizens. And media is the carrier and spreader of political discourse. Therefore, this paper is to explore the conception and attitudes of the African citizens through revealing the ideology embedded in the newspapers on Chinese model. Discourse analysis and critical discourse analysis provide a suitable method for analyzing the discourse about Chinese model, for it can help to illuminate the processes involved in the construction of the attitudes and ideology of African people through the media. The two methods are, however, often criticized for the risk of "cherry picking", which leads to obvious problems relating to representativeness and generalizability (Baker et al., 2008; Stubbs, 1994, 1997). Whats more, small data sets may also create the risk of neglecting linguistic patterns or pieces of ideologies, arguments and discourses.

To remedy for the defects discussed above, Hardt-Mautner (1995) and Paul Baker (2008) combines corpus linguistics with discourse analysis, emerging as Corpus-assisted discourse analysis. The correlational research generally focuses on the analysis of words and their textual context, through referring to word list, keywords, collocates and concordances of the note word in the corpus. This method breaks the boundary between qualitative and 
quantitative research in linguistic studies, and makes it possible for more detailed research on different levels of special texts, reduction of personal prejudice to the greatest extent, enhancement of text description and the persuasive power of the generation and reproduction of media language. It is widely used in the study of political discourse.

In 2015, Loretta Pyles and Juliana Svistova deconstruct the discursive constructions of postearthquake recovery in Haiti through corpus-assisted discourse analysis. In China, Qian Yufang (2016a, 2016b) successively carried out relative studies on the discursive construction of "low carbon economy" and "Chinese dream" in British mainstream newspapers based on this method. This paper serves to elaborate on discursive construction of "Chinese model" in African mainstream newspapers based on the same research method.

\section{DATA AND METHODS}

Pan-African News Agency, abbreviated as PANA, is a unified news agency with seven branches around Africa. It aggregates news produced primarily on the African continent about all areas of African life, politics, issues and culture. In addition to a least partial news collected by the reporters in headquarters, the news are mainly from the news agencies of member states.

The corpora in this paper consist of 44 articles, 43805 words, reporting on Chinese model from 2000 to 2017. All of these articles are from AllAfrica.com, which is a online news sites affiliated with Pan-African News Agency.

This paper, first, analyzes the Co-occurrence Network of Words around Chinese model (Figure 1.), acquired through KH Coder (Version 3. Alpha. 08L), a text analysis software, in order to explore the semantic relations between Chinese model and other high-frequency words, and to examine what fields or aspects are covered in reference to Chinese model when it is discursively constructed in the African newspapers. Next, the theme features of the news discourse will be discussed in terms of keywords, calculated by AntConc3.4.3 (Laurence Anthony, 2015). Finally, concordance lines, generated by AntConc3.4.3, serves to examine the contextual information and linguistic co-occurrence around the node word, through which pragmatic meaning and potential attitudes hidden in the news discourse will be revealed. Furthermore, semantic prosody around the node word will be analyzed to discover the attitudes and ideology of African society.

\section{RESULTS ANALYSIS AND DISCUSSION}

The following corpus results help to reveal what fields or aspects are covered in reference to Chinese model as is shown in the Co-occurrence Network of Words around Chinese model (Figure 1), what theme features embodied in news discourse observed from keywords (Table 1), and the concordance lines (Table 2, 3) and the hidden attitudes around Chinese model will be explored.

\section{Co-occurrence Network of Words around Chinese model}

This part is to explore the semantic relations between model (indicating Chinese model) and other high-frequency words, and to examine what fields or aspects are covered in reference to Chinese model when it is discursively constructed in the African mainstream newspapers. Assisted by KHcoder text analysis software, the Co-occurrence Network of Words around Chinese model is generated, involving four kinds of content words, namely, nouns, proper nouns, verbs, and adjectives. Figure 1 serves to present a general description of Chinese model in African newspapers. 
Figure 1. Co-occurrence Network of Words around Chinese model

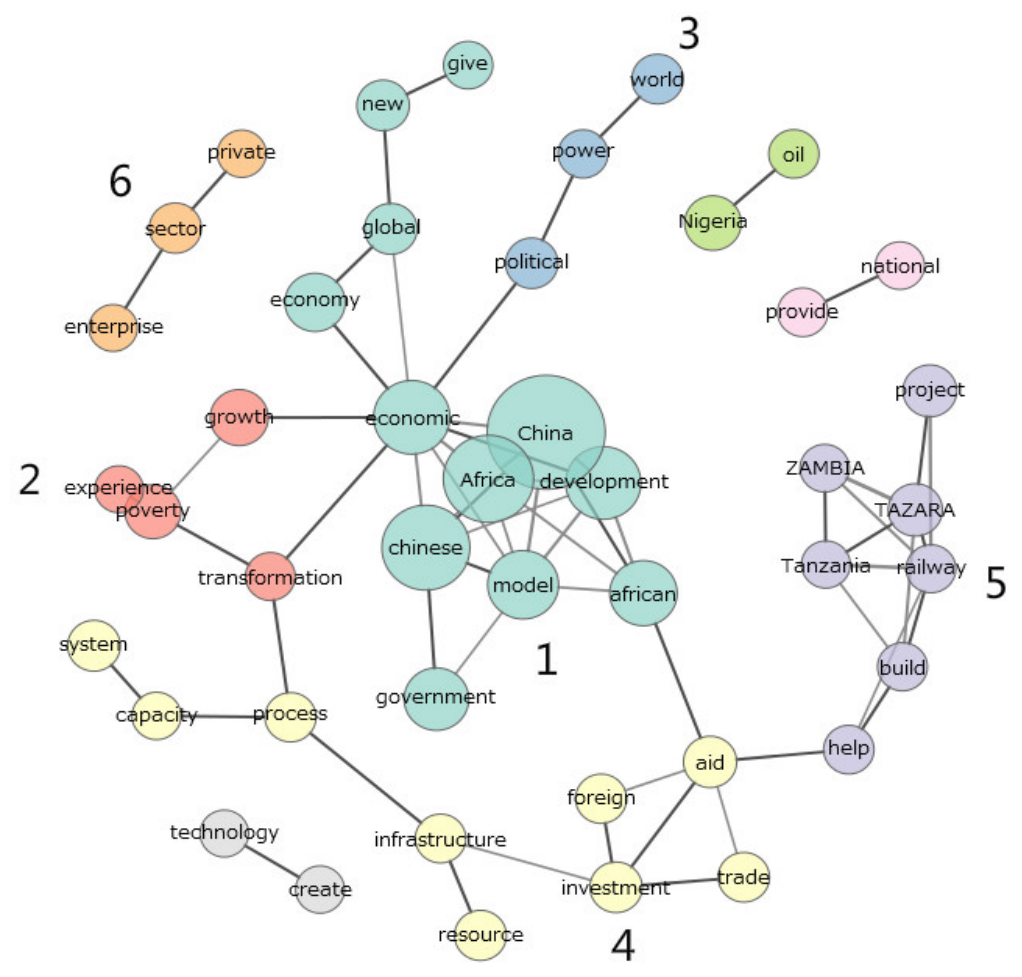

From the diagram, it can be observed that these words mainly covers six categories marked by different colors (automatically generated by the software). Cluster 1 in the largest scale reflects the influence of China's development, Chinese model, Chinese government on African economic development. Combining with Cluster 2, it can be seen that China's rapid development and the widely discussed "Chinese model" spurs on the African countries to consider Chinese model to relieve from poverty and realize rapid economic development and transformation. Cluster 3 indicates that the the booming economy of China also approves China's political strength, through which China's international influence has been promoted. As is demonstrated, in addition to Cluster 1, Cluster 4 also occupies a larger proportion in the African newspapers, which reflects the fact that the foreign aid and investment, commercial trade functions in facilitating the process of Africa's transformation, capacity building and optimization of various systems. Cluster 5 reflects the construction of Tanzania-Zambia Railway assisted by Chinese government. Cluster 6 is a reflection of the investment, trade and infrastructure construction of Chinese private enterprises on the initiative of Chinese government.

By analyzing the African newspapers on Chinese model, it is not hard to find that on the discussion of Chinese model, the focus of the African media is mainly on their economic development, China's investment, trade and cooperation, and expecting to draw upon Chinese development experience to relieve them from poverty.

\section{Keywords}

Keywords are a list of words whose frequency in a corpus is statistically significant when compared to the standards set by a reference corpus (Scott 1997). Keywords facilitate understanding of the main point of a text and constituting chains of repetition in text (Scott 2010). To take CLOB as the reference corpus, this paper uses AntConc to generate and select the top 20 keywords, listed in Table 1. 
Table 1: Keywords in the corpus

\begin{tabular}{cccccccc}
\hline Rank & Keywords & Frequency & Keyness & Rank & Keywords & Frequency & Keyness \\
\hline 1 & China & 519 & 2596.226 & 11 & transformation & 45 & 187.346 \\
2 & Africa & 327 & 1634.347 & 12 & oil & 52 & 179.459 \\
3 & economic & 227 & 735.281 & 13 & industrial & 46 & 167.185 \\
4 & development & 241 & 732.320 & 14 & trade & 66 & 163.451 \\
5 & model & 159 & 530.459 & 15 & military & 57 & 162.335 \\
6 & Tazara & 73 & 463.527 & 16 & zones & 30 & 152.06 \\
7 & poverty & 86 & 367.669 & 17 & investment & 53 & 128.579 \\
8 & aid & 72 & 281.904 & 18 & policy & 66 & 124.161 \\
9 & infrastructure & 54 & 219.718 & 19 & rural & 33 & 122.179 \\
10 & cooperation & 38 & 202.986 & 20 & agriculture & 23 & 116.986 \\
\hline
\end{tabular}

Based on the above 20 keywords and their contextual information, it was found that most of the reports are strongly associated with economy (economic, development, tazara, poverty, aid, infrastructure, transformation, industrial, trade, zones, investment, agriculture), and only a few reports involves with politics (policy).

From the aspect of economy, the African media mainly focuses on the model of poverty reduction, China's special economic zone (SEZ), industrial development, agricultural and rural development, rail-oriented infrastructure construction, investment, etc. To be more specific, the model of SEZ is frequently referred to in the corpus and has been recognized for encouraging investment, regional trade, manufacturing and exports, stimulating rapid economic growth and increasing employment, etc. Zambia is also encouraged by China's successful economic transformation by establishing special economic zones in some cities. Besides, in terms of industrial development, some African countries also hope to seek a more competitive industrial model to achieve sustainable development because a growing industrial sector is key to sustained overall economic development of a country which may bring multiplier effect, such as promotion of value addition and employment generation. African economists pointed out that Chinese industrial development model is also worth learning by Kenya and other African countries. In addition, in terms of rural development and agriculture, an official in Sudan praised Chinese model in the field of rural development for its focus on balanced development and on upgrading the level of living conditions at the rural areas to equal that of the urban areas, which deserves the third world countries with resources to learn. And Chinese agriculture model of small holder farming is highly praised as "a perfect example" and the agricultural demonstration centers created in Africa also helps African countries do better in agriculture development. It is noteworthy that the rural e-commerce model that Alibaba, China's Internet trading giant, explored in the development of rural areas has drawn the world's attention. It is believed that this model is also pitched for Africa in due course. Moreover, in regard to infrastructure construction, represented by railway transport, China receives compliment for its viable and cost effective railway network. On the ground that Tanzania Zambia Railway wins a good reputation among African continents, some African scholars argue that other railway projects should also be based on the same model of TAZARA.

In the political field, an introduction to China's democratic ruling party and political system is involved, as well as appreciation of Chinese government and its initiatives that play an important role in promoting social and economic development. Concretely speaking, it mainly includes the following two aspects. First, China's political system provides a model for collective leadership. The African media affirmed the democratic nature of the political system represented by the Communist Party of China (CPC), the National People's Congress (NPC) and the Chinese People's Political Consultative Conference (NPC), for CPC rose from the people and the "two sessions" helps the ruling party strongly convey the voices of the people. Through such party meetings, the main topics, policies, developments and amendments raised for 
discussions will demonstrate the benefit of collective thinking rather than individualism. Second, the successful implementation of the Chinese model is inseparable from correct guidance and efficient mechanisms or governing policies of China's government, to illustrate from the news, the principle of development-driven poverty reduction, gradual and strategic economic liberalization, an effective policy of the investment-driven and export-oriented growth, incentives to both private and public sector enterprises. By implementing effective policies, the government has ensured the efficient implementation of poverty reduction, guided the successful development of China, and balanced the relationship between the favorable environment for foreign investment and the effective development of domestic industry.

Therefore, it is important to point out that economy and politics go hand in hand, and the successful development of China's economy is inseparable from an efficient government and its policies.

\section{Concordance lines of Chinese model}

Concordance lines, the core of corpus linguistic research techniques, serves to provide further contextual information around Chinese model. Furthermore, through examining these concordance lines and attempting to uncover common patterns or prosodies indicated by the terms around the node word, the attitudes and cognition of various groups of people can be discovered. Assisted by AntConc3.4.3, this paper treats "model" as query words. Based on semantic prosody around "model", the concordances are slipped into two sets, positive (101 lines) and negative (21lines), among which the representative lines will be more detailed discussed.

Table 2. Concordance lines of "model"-positive

\begin{tabular}{|c|c|c|c|}
\hline 1 & Tazara rail line. China Hailed As World & Model & for Peaceful Big Power With Positive Reforms \\
\hline 2 & been lifted out of poverty is an attractive & model & for Africans, and not just for an elderly \\
\hline 4 & Combating Desertification - Inspirational Chinese & Model & !Thanks to research and concerted efforts, the \\
\hline 6 & development disparities. China's success with the SEZ & model & has caught the attention of African leaders eager \\
\hline 7 & it's important to learn from the Chinese & model & that has made rapid achievements in a short \\
\hline 10 & deep into rural China believes that its business & model & could help Africans in areas far from cities. \\
\hline 11 & added. Meanwhile, he described China's agriculture & model & a "perfect example" that the foundation is devoted \\
\hline 12 & surpasses the US in popularity as a development & model & "Public perceptions not only confirm China's important \\
\hline 13 & South Africa will utilize the Chinese & model & in its "re-industrialization" process, the presidency \\
\hline 14 & the field. We are so excited about this & model & It's a wonderful example where you can \\
\hline
\end{tabular}

Chinese model is hailed as a world model for the peaceful and remarkable development it has made in a short time since China's the reform and opening up. From the above concordances, it can be noticed that the African media tend to use the positive adjectives as "unique", "inspirational", "best", "attractive", "perfect", "wonderful" to modify Chinese model, which indicates the positive influence and their acknowledgment of Chinese model. Verbs as "learn", "replace”, "be held as", "believes", "help", "utilize", "surpass", "imitate”, "embrace”, confirms the African people's intention in borrowing Chinese model and their beliefs in its prospective benefits for African countries' development. Words as "unarguably", "important", "exactly", "calling for", "so excited", collocating with these verbs, or the speakers or writers has strengthened the tone. It shows the aspiration and enthusiasm of the African citizens on 
Chinese model. After tracing back to the original texts, some significant and representative concordances are picked to examine the original articles.

[1] And so it's important to learn from the Chinese model that has made rapid achievements in a short period from whence the country comes. Strategies by China should serve as a lesson for other developing countries, especially African countries, as the China-Africa Economic and Development Cooperation gains momentum.

[2] "We are so excited about this model. ..It's a wonderful example where you can combine Chinese technological expertise and innovation, doing it in a low cost way, so this is actually going to be affordable and distributable across Africa," he added.

Example 1 illustrates Africa's acknowledgement of China's rapid development, effective development strategies and Sino-Africa's economic cooperation, in the hope of drawing lessons from Chinese development model or experience. Example 2 not only confirms the effectiveness of Chinese model, but also its feasibility due to its affordability and distributability.

Table 3. Concordance lines of "model"-negative

\begin{tabular}{|l|r|l|l|}
\hline 1 & it you will see that the so-called & model & almost disappears." After a trip to China last \\
\hline 2 & the need for China to change its development & model & if there ever was one," says Wang Hui. \\
\hline 3 & been more doubt than consensus about the China & model & $\begin{array}{l}\text { "Prof. Wang Hui who studies Chinese intellectual } \\
\text { thought }\end{array}$ \\
\hline 5 & it remains to be seen if this Chinese & model & of development could be replicated else in countries \\
\hline 6 & Whether Zimbabwe can successfully copy the Chinese & model & depends more on what it does with it \\
\hline 7 & some people just don't want the Chinese & model & for apparent no reason whatsoever. No doubt it \\
\hline 8 & mining sectors, but along with the successful Chinese & model & $\begin{array}{l}\text { of development come serious problems. From Sudan, } \\
\text { Cam }\end{array}$ \\
\hline 9 & awareness that the continent cannot replicate the \\
China & model & and needs a different economic paradigm to suit \\
\hline 10 & But observers warn that transplanting the China & model & has its risks especially because Beijing is seen \\
\hline 11 & the Chinese people. This is definitely not a & model & suited to Ethiopian realties, although there is a \\
\hline 12 & is that neither the Western, nor the Chinese & model & would prove a viable alternative since both have \\
\hline
\end{tabular}

From the above concordances, "so-called", "if there was one", "more doubt than consensus" indicate that very few people doubts the existence of Chinese model. Tracing back to their original test, it is found that all of these doubt comes from an article, entitled "Chinese Model Showing Cracks[analysis]", in which it collects the evaluation of Chinese scholars on Chinese model. It also confirms the fact that different from abroad, Chinese model is more controversial at home. In several reports, words as "remain to be seen", "whether... can successfully copy..." demonstrate the uncertainty of its prospects for some African people. Negative words of copying Chinese model also exist in these African reports. Words as "awareness", "warn", "risks", "serious problems", express their worries, or even misunderstanding and prejudice some African people take towards Chinese model or replicating Chinese model. In order to gain insight into the causes, some significant concordances are picked to examine their original reports.

There are some comparatively objective views on Chinese model, as presented in Example 1 and 2. Some people hold the view that Africa need a different model to suit its own realities, instead of replicating the Chinese model. And some reckon that Africa should maintain the present status quo, for both western and Chinese model show more of their limitations than opportunities. The wisest option is to take the available opportunities from both quarters and use them in light of the local conditions: 
[1] In Africa where the Chinese footprint is growing there is also growing awareness that the continent cannot replicate the China model and needs a different economic paradigm to suit its own realities.

[2] The trouble is that neither the Western, nor the Chinese model, would prove a viable alternative since both have more limitations than opportunities. The wisest option would be to try to take the available opportunities from both quarters and use them in light of the local conditions.

In the process of carrying out Chinese model, some "serious problems" came out, such as overworking, under-paying and ill-treating.

[3] While disputes are a common feature of labour under capitalist conditions, what draws global media attention to China in Africa is the sometimes brutal boss-employee model practised by the continent's new imperial masters. Although China has come a long way in its domestic labour relations, mass social unrest, worker exploitation and walkouts over pay show the ugly side of the Red Dragon's rapid industrialisation.

From the above serious evaluation on Chinese model, even though these serious problems may only exist in peculiar situation, China should also be alert about misconducts of these private enterprises, and keep current implementation of Chinese model under strict supervision. Or it will tarnish China's friendly endeavors and good image that China has long been working for.

\section{CONCLUSION}

The prevalence of Chinese model embodies the world's overall recognition of China's achievements and its development model. As the bilateral relationships between China and Africa and their contacts and exchanges in various aspects grows closer, the great achievements China has made in a short time also spurs on African countries to consider Chinese model to aid them in achieving economic and social development.

Based on the analysis on the Co-occurrence Network of Words around Chinese model, keywords, concordance lines and semantic prosody, the following conclusions can be drawn: (1) On the discussion of Chinese model, the focus of the African media is mainly on their economic development, China's investment, trade and cooperation, and expecting to draw upon Chinese development experience to relieve them from poverty. (2) Most of the reports on Chinese model are strongly associated with economy, such as the model of poverty reduction, China's special economic zone (SEZ), industrial development, agricultural and rural development, rail-oriented infrastructure construction, investment, etc. And only a few reports involves with politics, in which China's democratic ruling party and political system is involved, as well as appreciation of efficient Chinese government and its policies that play an important role in ensuring the promotion of social and economic development. (3) On the point of replicating Chinese model in facilitating African development, the majority of Africans are affirmative of this approach. There are only a few publications in which people show their uncertainty and worries about the prospect of applying Chinese model in Africa. As for some negative evaluation, China should be alert and keep current implementation of Chinese model under strict supervision. As for the misunderstandings, it is also necessary for China to declare itself and clear up the misunderstandings in case that it will tarnish the two sides' sincere friendship.

\section{ACKNOWLEDGEMENT}

This work is supported by the National Social Sciences Fund Program "Critical discourse analyses of the cyber language violence" under Grant 15BYY057 


\section{Reference}

Anton Törnberg \& Petter Törnberg. Muslims in social media discourse: Combining topic modeling and critical discourse analysis[J]. Discourse, Context and Media, 2016(13), 132-142

Baker, P., C. Gabrielatos, M. Khosravinik, et al. A useful methodological synergy? Combining critical discourse analysis and corpus linguistics to examine discourses of refugees and asylum seekers in the UK press [J]. Discourse \& Society, 2008(3), 273-306.

Baker, P., C. Gabrielatos \& T. McEnery. Sketching Muslims: A corpus driven analysis of representations around the word 'Muslim' in the British press 1998-2009 [J]. Applied Linguistics, 2012(3): 255-278.

Bondi, M., \& Scott, M. (Eds.). Keyness in texts (Vol. 41) [M]. Amsterdam: John Benjamins Publishing, 2010.

Fairclough, N. Language and Power [M]. London: Longman, 1989.

Fairclough, N \& R. Wodak. Critical discourse analysis [A]. In: Teun van Dijk (ed.). Discourse as Social Interaction [C]. London: Sage Publications, 2013.

Hardt-Mautner, G. "Only Connect": Critical Discourse Analysis and Corpus Linguistics [R]. Lancaster: UCREL, 1995. Jian, Gao. Disputes and reflection on “Chinese model”[J]. CASS Journal of Political Science, 2011(03):72-85.

Loretta Pyles \& Juliana Svistova. Critical Discourse Analysis of Haiti Earthquake Recovery in New York Times Articles:Implications for Social Welfare Policies, Practices and Education[J]. Critical Social Work. 2015 (16), $59-77$.

Ramo, J. C. The Beijing Consensus [R]. London: Foreign Policy Centre, 2004.

Scott, M. PC analysis of key words-and key key words[J]. System. 1997, 25(2), 233-245.

Stubbs, Michael. Grammar, text, and ideology: computer-assisted methods in the linguistics of representation [J]. Appl. Linguist. 1994 (12), 20-223.

Stubbs, Michael. Whorf's children: critical comments on critical discourse analysis (CDA) [J]. Appl. Linguist. 1997(12), 100-116.

Wikipedia contributors. AllAfrica.com [Internet]. Wikipedia, The Free Encyclopedia; 2018 Jun 10, 23:18 UTC [cited 2019 Jan 22]. https://en.wikipedia.org/w/index.php?title=AllAfrica.com\&oldid=845311201.

Yufang, Qian. A study of discourse construction on low carbon economy in British mainstream newspapers [J]. Foreign Languages and Their Teaching, 2016(2):25-35.

Yufang, Qian \& Xiaoqin, Huang. A study of discourse Construction on "Chinese Dream” in British and American Mainstream Newspapers [J]. Journal Of Tianjin Foreign Studies University, 2016(4):15-21. 